\title{
O NOVO CONCEITO DE PESSOA COM DEFICIÊNCIA E SUA \\ APLICABILIDADE POR ÓRGÃOS FISCALIZADORES OU \\ RECONHECEDORES DE DIREITOS ESTATAIS
}

\author{
Cahue Alonso Talarico ${ }^{131}$ \\ Ricardo Alves Sampaio ${ }^{132}$
}

Recebido em: 14/08/2019

Aprovado em: 06/02/2020

\begin{abstract}
RESUMO
O presente artigo tem como objetivo abordar a mudança conceitual de pessoa com deficiência e a dificuldade de assimilação desta alteração nos órgãos de fiscalização ou reconhecedores de direitos estatais. A Convenção de Nova Iorque, sobre direitos da pessoa com deficiência, que ingressou no ordenamento jurídico brasileiro com status de normal constitucional, conforme o processo legislativo previsto no art. $5^{\circ}, \S 3^{\circ}$, da Constituição Federal, mudou substancialmente as normas brasileiras. A partir de então, pretende-se que o processo permanente de inclusão seja mais efetivo, derrubando intolerâncias, perseguindo os ideais de igualdade, universalização de direitos e a efetiva tutela dos direitos da pessoa com deficiência, já que esta tem sua situação mais ou menos agravada, tendo em vista as condições do meio lhe sejam mais ou menos favoráveis. Destarte, serão analisados dois órgãos de fiscalização, as Delegacias do Trabalho e o Ministério Público do Trabalho e o Instituto Nacional do Seguro Social - INSS, enquanto reconhecedor de direitos. Para tanto, observar-se-á, por meio de pesquisa qualitativa, a legislação que vem sendo aplicada por estes órgãos estatais, após a referida mudança conceitual.
\end{abstract}

Palavras-chave: Novo Conceito. Direitos. Pessoa com deficiência. Órgãos de fiscalização. Benefício assistencial.

\section{INTRODUÇÃO}

\footnotetext{
${ }^{131}$ Doutorando em Direito pela Universidade Católica de São Paulo - PUC/SP. Professor. Advogado.

${ }^{132}$ Doutorando em Direito pela Universidade Católica de São Paulo - PUC/SP. Professor da Universidade do Estado da Bahia - UNEB. Advogado.
} 
A Constituição Federal de 1988 reservou papel de destaque aos tratados internacionais que dispõem direitos humanos. Direitos dessa qualidade, positivados no ordenamento jurídico brasileiro, possuem um regime jurídico ímpar dentre todos os outros temas presentes no texto constitucional. Para tanto, ao serem submetidos ao processo legislativo previsto no art. $5^{\circ}, \S 3^{\circ}$, da Lei Maior, com a devida aprovação, passarão a ser normas constitucionais e espécies de tratados poderão trazer novos dispositivos de igual valor positivo, capazes de revogar implicitamente alguma regra que restrinja um direito fundamental já existente, ou ainda trazer novos direitos humanos ao caráter legal de direito fundamental junto ao ordenamento jurídico brasileiro.

Até a presente data, apenas dois tratados internacionais passaram por este processo de ingresso com caráter de emenda constitucional, a Convenção de Nova York e o Tratado de Marraquexe $^{133}$. Na realidade, percebe-se a importância para o Brasil das convenções internacionais de proteção das pessoas com deficiência. De fato, todos os tratados até agora aprovados com "equivalência de emenda constitucional" no Brasil dizem respeito às pessoas com deficiência (o último, especificamente relativo à deficiência visual).

No que concerne à referida Convenção de Nova York, houve várias inovações, dentre elas a de não se confundir deficiência com incapacidade. Neste jaez, a deficiência é considerada apenas um fator que gerará impedimentos maiores ou menores conforme, as barreiras externas forem reduzidas ou eliminadas por medidas de acessibilidade.

Nesse sentido, a Convenção Internacional Sobre os Direitos da Pessoa com Deficiência, assinada em Nova York, em 30 de março de 2007, trouxe conceito mais adequado ao mundo contemporâneo:

Artigo 1 (...) Pessoas com deficiência são aquelas que têm impedimentos de longo prazo de natureza física, mental, intelectual ou sensorial, os quais, em interação com diversas barreiras, podem obstruir sua participação plena e efetiva na sociedade em igualdades de condições com as demais pessoas.

O referido conceito foi constitucionalizado pelo Brasil ao ratificar a Convenção sobre os Direitos das Pessoas com Deficiência, aprovada pelo Decreto Legislativo no 186/2008, de acordo com o procedimento previsto no artigo $5^{\circ}, \S 3^{\circ}$, da Constituição Federal, e promulgada pelo Decreto $n^{\circ} 6.949 / 09$.

${ }^{133}$ DLG n $^{\circ} 186$, de 2008, DEC nº 6.949, de 2009, DLG n²61, de 2015, DEC nº 9.522, de 2018. 
O novo conceito constitucional de pessoa com deficiência traz dois grandes avanços em não tratar tais pessoas como incapazes para o trabalho e para a vida independente e não limitar a definição sob o aspecto médico acerca do impedimento físico, mental, intelectual ou sensorial, mas incluir o elemento social mediante a análise do impedimento em interação com as barreiras sociais. Em síntese, o conceito de deficiência é uma questão social, observada a partir de análise de uma equipe multidisciplinar e não apenas sob uma constatação médica.

Neste artigo serão abordadas as atuações fiscalizatórias das Delegacias do Trabalho e do Ministério Público do Trabalho - MPT no que diz respeito aos direitos da pessoa com deficiência no mercado de trabalho e a respectiva utilização do novo conceito da pessoa com deficiência como instrumento de tutela, garantia e inclusão de direitos. Por outro lado, observar-se-á a atuação do Instituto Nacional do Seguro Social - INSS, como autarquia federal responsável pela concessão de benefícios previdenciários e assistenciais às pessoas com deficiência.

Por meio de pesquisa qualitativa se verificará se as mudanças atendem ou não a mudança do modelo trazido pela Convenção de Direitos da Pessoa com Deficiência.

\section{A HISTÓRIA DA PROTEÇÃO DA PESSOA COM DEFICIÊNCIA}

A proteção dos direitos das pessoas com deficiência pode ser dividida em quatro momentos históricos:

\subsection{Segregação}

Em um passado não tão remoto, havia intolerância com relação a essas pessoas. A deficiência representava impureza, pecado ou um castigo divino.

Num primeiro momento, a família e a sociedade de um modo geral não apenas não se importavam com as pessoas com deficiência, mas as segregavam. As famílias escondiam essas pessoas do restante da sociedade, cujos elementos as olhavam com certa repulsa.

Rodrigues (2015) esclarece que:

Durante muitos séculos, as pessoas com deficiência eram consideradas "inválidas" e socialmente inúteis. Neste contexto de quase barbárie, a política de segregação formulada 
no final do século XIX e aplicada até a década de 1940, impondo a internação definitiva em instituições fechadas, representou um progresso humanitário.

\subsection{Invisibilidade}

Com o passar dos anos, tais pessoas frequentemente eram completamente ignoradas. A sociedade não as enxergava. Apesar de não haver mais aquele sentimento de repulsa, também, não existia qualquer preocupação com o respeito à dignidade delas. Era como se tais pessoas não fizessem parte da sociedade.

\subsection{Integração}

Contrapondo-se à ideia de isolamento, surgiu um movimento de integração dessas pessoas, com a intenção de adaptar o meio social a elas, permitindo-lhes um melhor convívio em sociedade.

Entretanto, a deficiência era tratada como uma doença a ser curada e, em razão disso, a preocupação era apenas assistencialista, cujo objetivo seria a "cura desse mal".

A deficiência era um problema exclusivo da pessoa e de sua família, devendo aquela adaptar-se à sociedade e ao seu modo de vida. Não havia a preocupação desta em acolher essa pessoa, por exemplo, um aluno com deficiência física deveria primeiro resolver a sua dificuldade de ir à escola, sem que a instituição tivesse a preocupação de estar adaptada fisicamente às dificuldades desse aluno.

Não havia a preocupação com a partição dessas pessoas na sociedade. O sentimento era de piedade, pois se acreditava que essas pessoas não tinham condições de participar.

\subsection{Inclusão}

A partir da década de 80, pautada sobre a ótica da efetivação prática dos Direitos Humanos, começa a surgir a ideia de que não bastaria unicamente integrar, seria preciso incluir essas pessoas, dando origem ao que se convencionou chamar de sociedade inclusiva (MAYOR, 2011).

Segundo esse entendimento, todas as pessoas têm igual valor e aquelas com alguma deficiência fazem parte da diversidade humana, não se tolerando qualquer tipo de discriminação. A sociedade também precisa preparar-se para receber essas pessoas, por exemplo, adaptando 
fisicamente as escolas e o transporte público. A sociedade inclusiva, portanto, está alicerçada no respeito e na valorização das diferenças. Nesse contexto, são criados diversos documentos internacionais referentes à pessoa com deficiência.

O primeiro tratado que exigiu dos Estados-Partes a adoção de medidas protetivas da pessoa com deficiência surgiu em 1971 com a Declaração de Direitos do Deficiente Mental. O artigo 2º́ já deixava claro o direito à capacitação profissional das pessoas com esses impedimentos.

A partir daí, percebe-se que o que impede a participação plena dessas pessoas são as diversas barreiras existentes na sociedade. Ou seja, é preciso se eliminar o obstáculo para que tais pessoas exerçam seus direitos e isso não é um ônus apenas da pessoa que possui alguma limitação, mas de toda sociedade. Eliminando as barreiras, a participação ocorrerá em igualdade de condições.

\section{A EVOLUÇÃO DO CONCEITO DE DEFICIÊNCIA}

Os primeiros documentos que surgiram disciplinando os direitos das pessoas com deficiência não traziam definição de quem estaria inserido nessa categoria. O conceito é importante, pois confere maior segurança jurídica, dirimindo dúvidas sobre quem merece a proteção normativa, ampliando a garantia de direitos.

Em 1971, a Declaração de Direitos do Doente Mental não estabelecia quem eram os doentes mentais, ficando ao médico o critério de estabelecer quais pessoas se encaixavam no conceito.

Já em 1975, a Declaração de Direitos das Pessoas com Deficiência utilizava o termo "pessoas deficientes" no item 1 e referia-se a:

(...) qualquer pessoa incapaz de assegurar por si mesma, total ou parcialmente, as necessidades de uma vida individual ou social normal, em decorrência de uma deficiência, congênita ou não, em suas capacidades físicas ou mentais.

Esse conceito deixou de lado as pessoas que tinham limitações sensoriais e intelectuais.

O Programa de Ação Mundial para Pessoas Deficientes de 1982, embora não apresentasse o conceito, deixava claro existir a deficiência física, mental e sensorial no item 35 da Descrição Geral que in verbis:

37. (...) Na maioria dos países, pelo menos uma em cada dez pessoas tem uma deficiência física, mental ou sensorial e a presença dessa deficiência repercute de forma negativa em pelo menos $25 \%$ de toda a população. 
A Declaração de Salamanca de 1994 limitou-se a disciplinar o assunto relativo à educação, com o objetivo de atribuir a todos igualmente oportunidade de ensino. Contudo, não há definição do que seja deficiência.

No sistema interamericano, a Convenção Contra Todas as Formas de Discriminação contra a Pessoa com Deficiência, em seu artigo $1^{\circ}$ define deficiência como "uma restrição física, mental ou sensorial, de natureza permanente ou transitória que limita a capacidade de exercer uma ou mais atividades essenciais da vida diária, causada ou agravada pelo ambiente econômico e social".

Em 2007, a Convenção Internacional sobre Direitos da Pessoa com Deficiência, também chamada de Convenção de Nova Iorque, em seu artigo $1^{\circ}$, traz a seguinte definição:

Pessoas com deficiência são aquelas que têm impedimentos de longo prazo de natureza física, mental, intelectual ou sensorial, os quais, em interação com diversas barreiras, podem obstruir sua participação plena e efetiva na sociedade em igualdades de condições com as demais pessoas.

Com isso, apesar da vagueza da Convenção, colocou-se fim às dúvidas sobre quem está acobertado pelas normas protetivas das pessoas com deficiência. Ficou claro que as limitações devem ser de longo prazo, não sendo considerada pessoa com deficiência aquela pessoa que tenha limitações por um pequeno período.

Não é possível mais se confundir pessoa com necessidades especiais com pessoa com deficiência, pois a primeira é expressão bem mais abrangente e não corresponde fielmente à segunda. Uma mulher grávida tem necessidades específicas, mas não se enquadra no conceito de pessoa com deficiência introduzido pela Convenção de Nova Iorque.

Não importa a natureza da limitação, seja ela física, mental, intelectual ou sensorial, tais obstáculos deverão ser, na medida do possível, ultrapassados para permitir a plena participação dessas pessoas na sociedade.

Ribeiro (2010) lembra a explicação apresentada por Laís Vanessa de Carvalho, ilustrando com uma equação matemática o impacto do ambiente em relação à funcionalidade do indivíduo.

Ou seja, se o ambiente não trouxer qualquer barreira, ser-lhe-á atribuído valor zero que, multiplicado por qualquer valor atribuído à limitação funcional, terá como resultado zero.

Conforme brilhantemente expõe o autor, o "que esta equação revela é que a limitação do indivíduo é agravada ou atenuada de acordo com o meio onde está inserida, sendo "zero" (ou nula) 
quando o entorno for totalmente acessível e sem barreiras". E conclui: “quanto maior o número de obstáculos, maior será o reflexo na deficiência, quando associada à limitação do indivíduo”.

Como a Convenção Internacional sobre Direitos da Pessoa com Deficiência fora aprovada conforme processo disciplinado no artigo $5^{\circ}, \S 3^{\circ}$, da Constituição de 1988, tendo status de norma constitucional, deverá ser adotado o conceito nela previsto, em detrimento de outros menos abrangentes. O referido conceito foi seguido pela Lei Brasileira de Inclusão (Lei nº13. 146/15).

Dessa forma, o ambiente de trabalho deve estar livre de qualquer barreira que impeça o exercício profissional pela pessoa com deficiência. Todas as pessoas serão beneficiadas por essa eliminação e não apenas as pessoas com deficiência, pois o ambiente seguirá o desenho universal. Ora, mesmo alguém que, por exemplo, tenha a mobilidade temporariamente reduzida, poderá exercer a sua atividade laboral. Há vantagem, portanto, para todos: empregados e empregadores.

\subsection{Dos resquícios do modelo médico}

Como dito anteriormente, com o advento da Convenção de Direitos da Pessoa com Deficiência, foi abandonado o modelo médico e adotado o modelo social de definição de pessoa com deficiência.

Apesar disso, ainda existem resquícios do modelo médico na legislação brasileira, em afronta à norma constitucional. Tais resquícios acabam por refletir em decisões judiciais baseadas nesse conceito já ultrapassado.

Como ainda em vigor, é importante analisar o artigo $4^{\circ}$ do Decreto n 3.298 de 1999 que ainda categoriza as pessoas com deficiência em deficiência física, auditiva, visual, mental e múltipla.

Tal categorização vai de encontro à principiologia da Convenção. O rol previsto no decreto n 3.298 de 1999, mesmo após as modificações trazidas pela Convenção de Nova Iorque, é exemplificativo.

Da mesma forma deve ser encarado o Decreto n 5.296/04, que, segundo Araújo (2016, p.04):

Aqui, ao falar da Convenção da ONU há que mencionar uma modificação sensível ao sistema até então existente. A Convenção da ONU altera de forma radical o conceito de pessoa com deficiência. Deixa o conceito médico até então vigente no Brasil, por força de um decreto regulamentar (Decreto $\mathrm{n}^{\circ}$ 5296-2004) para adotar um conceito ambiental, 
muito mais preocupado com as barreiras existentes na realidade do indivíduo do que apenas e tão somente no aspecto médico.

Aliás, esse Decreto - como todas as demais normas - deve ser interpretado à luz da referida Convenção. Dessa forma, existem outros impedimentos que não estão inseridos neste Decreto que, em conjunto com as barreiras, impedem a participação plena e efetiva da pessoa na sociedade. Se tais barreiras não puderem ser superadas, estar-se-á diante de pessoa com deficiência.

Uma pessoa com TDAH (Transtorno do Déficit de Atenção com Hiperatividade), por exemplo, pode estar inserida nesse contexto, principalmente em relação ao exercício do direito à educação.

Uma pessoa com visão monocular pode ou não ser considerada pessoa com deficiência, a depender das barreiras enfrentadas no exercício dos seus direitos. O que é preciso ter em mente é que, a partir da Convenção, a análise que deve ser feita é casuística, não podendo se falar em presunção de qualquer tipo de incapacidade ou inaptidão.

Aliás, a presunção é de capacidade, não podendo se confundir deficiência com ineficiência. Uma pessoa com deficiência pode exercer seu direito ao trabalho em igualdade de condições com as demais pessoas, desde que não existam barreiras que a impeçam de praticar tal atividade.

Uma pessoa com TEA (transtorno do espectro autista), i. ex., pode plenamente desempenhar uma atividade profissional com maestria. Entretanto, o ambiente de trabalho deve ser adaptado às suas necessidades, pois do contrário se tornará insalubre a ela. Se houver dificuldade na socialização e hipersensibilidade auditiva, colocá-la sem qualquer preparo no atendimento ao público poderá ser desastroso.

Entretanto, percebendo seus potenciais e com ambiente propício, seu desempenho poderá ser altíssimo, proporcionando grandes vantagens ao empregador. Tome-se como exemplo de sucesso o trabalho desempenhado pela Specialisterne que forma e insere pessoas com autismo no mercado de trabalho ${ }^{134}$. Uma vez notadas pelos empregadores e percebendo suas potencialidades, a preocupação não será apenas de cumprir cota com medo da punição estatal, mas pela satisfação de ver as tarefas bem desempenhadas e o lucro obtido. Como tais pessoas estavam excluídas do convívio social, essas potencialidades eram - e ainda o são - desconhecidas, o que inibe a sua

\footnotetext{
${ }^{134}$ Specialisterne é uma fundação dinamarquesa que tem por premissa a inclusão das pessoas com TEA (transtorno do espectro autista) no mercado de trabalho. Conforme ela mesmo define, eles utilizam as habilidades incomuns em pessoas que não estão no espectro como um diferencial no mercado de trabalho. $\mathrm{O}$ fato de não tolerarem o erro, $\mathrm{o}$ apego à rotina e a atenção aos detalhes tornam tais pessoas valiosas no mercado de trabalho. Disponível em: http://br.specialisterne.com/servicos/formacao-na-specialisterne/. Acesso em 10/04/2019
} 
contratação. Permanece a ideia que tais pessoas representam um custo aos empregadores e não um investimento como os demais trabalhadores.

Na medida em que estiverem desempenhando bem a função, o empregador não terá mais preconceito na contratação, ao contrário, desejará ter mais empregados com essas características. Essa categorização ainda existente em algumas normas acaba dificultando a inclusão da pessoa com deficiência na sociedade e, consequentemente, no mercado de trabalho.

\section{DOS ÓRGÃOS ESTATAIS FISCALIZADORES E SUAS ADERÊNCIAS AINDA AO CONCEITO MÉDICO DE PESSOA COM DEFICIÊNCIA EM DETRIMENTO DO CONCEITO SOCIAL}

\subsection{Do Direito ao Trabalho}

Ao Ministério Público do Trabalho - MPT cabe fiscalizar a inserção ou não inserção da pessoa com deficiência no mercado de trabalho com o auxílio do Ministério Federal que tenha na sua competência o Trabalho, por meio das Delegacias Regionais do Trabalho.

O trabalho é um dos direitos sociais garantidos pela Constituição. Seu art. $7^{\circ}$, além de prever os direitos trabalhistas básicos, garantidos a todos os trabalhadores, ainda explicita, no inciso XXXI, que há proibição de qualquer discriminação no tocante a salário e critérios de admissão do trabalhador portador de deficiência.

A Convenção de Nova York corrobora esta mesma linha de pensamento e cuida do direito ao trabalho em seu artigo 27. Vale ressaltar sua preocupação com as condições do ambiente de trabalho, o qual deve ser "aberto, inclusivo e acessível a pessoas com deficiência". Também dispõe sobre "condições seguras e salubres"; proteção contra o assédio; treinamento profissional e continuado; assistência na procura e manutenção do emprego; ações afirmativas; adaptações razoáveis no local; entre outras necessárias previsões.

Em relação ao trabalho em empresas privadas, existe a obrigação legal de cumprir certa quota entre seus empregados. Nos termos da Lei $n^{\circ}$ 8.213/91, art. 93:

As empresas com cem ou mais empregados estão obrigadas a preencher de dois a cinco por cento de seus cargos com beneficiários da Previdência Social reabilitados ou com pessoas com deficiência habilitadas, na seguinte proporção: até duzentos empregados, 
dois por cento; de duzentos e um a quinhentos empregados, três por cento; de quinhentos e um a mil empregados, quatro por cento; ou mais de mil empregados, cinco por cento.

O cumprimento formal da quota, sem a devida adaptação, acarreta um aumento no preconceito existente. É preciso lembrar que a oferta de apoio, quando necessária, deverá ocorrer ainda que a inserção no mercado de trabalho tenha ocorrido por colocação competitiva, conforme estipula o artigo 35, I, do Decreto 3.298/99.

Além de a adaptação razoável ser um direito da pessoa com deficiência, o empregador deve realizá-la, percebendo que se trata de investimento e não um custo para a empresa. Rompendo-se as barreiras, a pessoa com deficiência irá produzir como os demais empregados, gerando lucro.

Entretanto, a falta de adaptação razoável, além de ser uma forma de discriminação - ainda que por omissão -, deixará seu funcionário ocioso, o que não é conveniente para ambos os lados: empregado e empregador. Além da ociosidade, a falta de adaptação gera conflitos entre empregados, aumentando cada vez mais o preconceito e a concepção capacitista em relação à pessoa com deficiência; reafirmando que ela é incapaz, dentre outras coisas, de produzir.

Prova disso pode ser vista no Recurso Ordinário nº 1000710-23.2017.5.02.0714 julgado pela $1^{\text {a }}$ Turma do Tribunal Regional do Trabalho da $2^{\text {a }}$ Região. Neste caso, uma pessoa com deficiência visual não conseguia desempenhar sua função, pois o computador não era adaptado às suas necessidades (tela ampliada e cor de fundo diferente). Em razão do desempenho abaixo do esperado, a supervisora declarou que quem não enxergava direito não deveria trabalhar lá. Observese parte do julgado:

A autora comprovou por meio de testemunha que foi ofendida por meio do comentário da supervisora que disse que "se não consegue enxergar, não deveria trabalhar". Tal declaração tem natureza discriminatória, considerando a condição especial da trabalhadora (deficiência visual) e da obrigação da empresa de garantir ambiente de trabalho acessível, inclusivo e livre de discriminação.

Ao ouvir tal comentário, é certo que houve desvalorização do trabalho da reclamante, causando-lhe diminuição da sua dignidade, interna e externamente, uma vez que a declaração ofensiva foi presenciada por outra empregada.

Portanto, a reparação é devida.

Fica claro o despreparo da supervisora, mas, também, é evidente que uma adaptação simples evitaria a ocorrência do fato e o aumento do preconceito. A sociedade, de um modo geral, ainda tem uma visão capacitista: que a pessoa com deficiência é ineficiente, incapaz de produzir e de competir em igualdade de condições. Na verdade, o que falta é perceber a necessidade da ruptura 
de barreiras; uma verdadeira igualdade substancial e não apenas formal, pois tais pessoas estão em uma situação diferente.

Gonzaga (2012) lembra que as instituições especializadas podem intermediar a colocação no mercado de trabalho, sobretudo na forma de colocação seletiva. Lamentavelmente, é comum que as empresas contratem as pessoas com deficiência apenas para cumprir a cota, sequer permitindo o desempenho da função. Isso pode ser notado no Recurso Ordinário no 1001919 70.2016.5.02.0711 julgado pelo Tribunal Regional do Trabalho da $2^{\mathrm{a}}$ Região:

RECURSO ORDINÁRIO. PESSOA COM DEFICIÊNCIA. ÓCIO FORÇADO. DANO MORAL CARACTERIZADO. INDENIZAÇÃO DEVIDA. No caso, restou comprovado que a empregada, pessoa com deficiência, foi admitida pela ré, participou de curso de capacitação, contudo, ao final do mesmo não assumiu o posto de trabalho, permanecendo em casa, comparecendo esporadicamente à empresa apenas para assinar a folha de ponto, submetida a uma situação de ócio. Conquanto remunerada, esta circunstância não afasta o caráter ilícito, pois há violação da lei 13.146/2015 (Estatuto da Pessoa com Deficiência), cujo escopo é a inclusão social e a garantia plena e efetiva do acesso às relações de trabalho em igualdade de oportunidades. A contratação não passou de uma formalidade, um "número" a mais na folha de pagamento para cumprimento da cota legal. A efetividade do direito ao trabalho (consagrado no art. 6o da Constituição Federal) e à inclusão em igualdade de oportunidade (explicitada no EPCD) não se concretizou. Caracterizado o dano, pois a situação fática atenta contra a autoestima, a autodeterminação e o sentimento de utilidade da reclamante, a reparação é de rigor. Recurso patronal desprovido.

A fiscalização, portanto, no cumprimento da Lei $n^{\circ} 8.213$ de 199, está sendo falha. Não devem ser analisados apenas os números de empregados com e sem deficiência contratados, mas, principalmente, o número de pessoas que efetivamente estão desempenhando as suas funções e se há as adaptações razoáveis de acordo com as necessidades individuais. Se isso não estiver de fato ocorrendo, estar-se-á aumentando ainda mais o preconceito e a visão capacitista.

Vale ressaltar que as adaptações devem ser analisadas de acordo com as necessidades do indivíduo. Não adianta categorizar as limitações e rotular as pessoas de acordo com suas limitações, pois isso não é incluir. A pessoa não pode ser etiquetada de acordo com suas limitações e acreditar que a adaptação feita para um servirá para todas. Esse tipo de conduta se trata de um depósito de seres humanos no ambiente de trabalho. A inclusão é a inserção de forma digna e efetiva dessas pessoas no mercado de trabalho. Como já mencionado, o Ministério do Trabalho por meio das Delegacias Regionais do Trabalho e o Ministério Público do Trabalho, tem a missão de fiscalizar o cumprimento das cotas. 
Observe-se que tais instituições têm o dever de analisar, também, o cumprimento efetivo delas, ou seja, se não está havendo algum tipo de discriminação, ainda que por omissão, como a falta de adaptação razoável ou apoio necessário para o exercício do direito.

\subsection{Da possibilidade de aumento na contratação}

A fiscalização adequada proporciona uma maior contratação das pessoas com deficiência, além de promover sua inclusão social. Segundo o Ministério da Economia, em 2018 46,9 mil pessoas com deficiência e reabilitados foram contratados ${ }^{135}$. A fiscalização exigiu uma mudança de atitude dos empregadores, reconhecendo que eles preferem contratar pessoas com limitações mais leves, pois a exigência de adaptações é menor. Como bem salientou João Paulo Teixeira, chefe da Divisão de Fiscalização para Inclusão de Pessoas com Deficiência e Combate à Discriminação no Trabalho ${ }^{136}$ :

É necessária uma mudança de atitude nas empresas, para deixar de enxergar unicamente a deficiência dessas pessoas e passar a identificar seus talentos e capacidades. Por enxergar somente a deficiência, algumas empresas preferem pessoas com deficiência leve, para não haver o esforço de modificar o ambiente de trabalho.

E mais, além da fiscalização, é preciso orientar os empregadores, demonstrando que a pessoa com deficiência não é um custo imposto pela lei. Mas que essas pessoas - na verdade as adaptações - são um investimento que futuramente lhes trará dividendos. É possível que tais empregados, uma vez estimulados, desempenhem a função com maior determinação que os demais, aumentando a possibilidade de lucro.

Além disso, uma empresa que possua empregados diversos tende a atrair públicos diversos, desde que saiba como proporcionar tal atrativo. Lamentavelmente, o que se percebe é que a inclusão de tais pessoas não tem sido espontânea. Conforme divulgado pelo Ministério da Economia, aumenta o número de empregados com deficiência proporcionalmente ao aumento de fiscalização.

135 Disponível em: http://www.economia.gov.br/noticias/2019/02/contratacao-de-pessoas-com-deficiencia-baterecorde-apos-fiscalizacao-do-trabalho. Acesso em 30/04/2019

136 Disponível em: http://trabalho.gov.br/noticias/6856-contratacao-de-pessoas-com-deficiencia-bate-recorde-aposfiscalizacao-do-trabalho. Acesso em 01/06/2019. 
Apesar do avanço, o número de pessoas com deficiência no mercado de trabalho ainda é muito tímido. Segundo o IBGE, aproximadamente $25 \%$ das pessoas possuem algum tipo de deficiência ${ }^{137}$. Entretanto, apenas $1 \%$ delas está empregada.

\subsection{Da atuação fiscalizatória das Delegacias do Trabalho}

É da competência da União a execução da inspeção do trabalho (CF, inciso XXIV do art. 21). Esta atividade, por intermédio do Ministério do Trabalho e Emprego (MTE), é realizada pelos servidores integrantes da carreira de auditor-fiscal do trabalho, cuja atividade é prevista na lei n. ${ }^{\circ}$ 10.593/2002, cujas atividades são regularmente exercidas nas Delegacias do Trabalho - DRT.

A DRT, hoje denominada SRTE, é a representação do Ministério da Economia ${ }^{138}$ em nível regional. Apesar de ser um termo muito utilizado pela população em geral, é preciso pontuar que esta nomenclatura - Delegacia Regional do Trabalho (DRT) - não mais existe. Este era o termo designado nas normas regulamentadoras originais, quase todas elaboradas no final da década de 70. Muitas delas, contudo, mesmo que tenham sido alteradas, ainda possuem estas titulações desatualizadas, assim como a CLT.

O termo DRT foi substituído por SRTE, que significa Superintendência Regional do Trabalho e Emprego. Cada estado brasileiro possui uma SRTE, que é a representação do Ministério do Trabalho em nível regional, com um Superintendente Regional do Trabalho, que é a autoridade máxima dentro daquele órgão regional.

A SRTE possui algumas funções de extrema relevância para a sociedade e também, para o trabalhador, habitualmente o polo hipossuficiente em uma relação de emprego. Assim, é no âmbito da SRTE e das Gerências Regionais do Trabalho e Emprego (GTRE), que se presta orientação e apoio ao cidadão nas questões relativas ao universo do direito do trabalho.

Também fica a cargo da SRTE a fiscalização relacionada ao cumprimento da legislação trabalhista, segurança e saúde do trabalhador e até mesmo do Fundo de Garantia por Tempo de Serviço (FGTS).

Diante dessas e de outras atribuições, é possível perceber que o papel da SRTE é de suma importância na estrutura do Ministério do Trabalho, pois seu atendimento regionalizado e

\footnotetext{
137 CENSO 2010. Disponível http://censo2010.ibge.gov.br/noticiascenso?busca=1\&id=3\&idnoticia=2170\&view=noticia. Acesso em: 10 de maio. 2019

138 Através da MP n870/2019, a estrutura do Ministério do Trabalho agora integra o Ministério da Economia.
} 
descentralizado proporciona um alcance maior das práticas necessárias para o bom andamento da físcalização, orientação aos cidadãos e segurança das relações de trabalho.

Ao auditor-fiscal do trabalho incumbe assegurar a observância das disposições legais e regulamentares, inclusive às relacionadas à segurança e à medicina laboral, no âmbito das relações de trabalho. Pode lavrar autos de infração, inclusive com autuação indireta, bem assim como os termos de compromisso.

Enfim, os auditores-fiscais do trabalho cumprem uma função tanto de índole preventiva, como repressiva, e exercem função essencial à observância da ordem jurídica laboral, especialmente, com a realização das ações fiscalizatórias.

De acordo com o Ministério do Trabalho e Emprego, cabe aos auditores fiscais inspecionar e fiscalizar as empresas que possuem no mínimo 100 empregados a contratarem de $2 \%$ a $5 \%$ para os cargos com beneficiários reabilitados ou pessoa com deficiência, como afirma o art. 93 da Lei n. ${ }^{\circ} 8213 / 91$ com o intuito de coibir as irregularidades cometidas pelas empresas quanto ao cumprimento da legislação alusiva ao trabalho das pessoas com deficiência.

Segundo o Decreto № $3.298 / 99$, no art. $36, \S 5^{\circ}$, diz que:

Compete ao Ministério do Trabalho e Emprego estabelecer sistemática de fiscalização, avaliação e controle das empresas, bem como instituir procedimentos e formulários que propiciem estatísticas sobre o número de empregados com deficiência e de vagas preenchidas

As medidas a serem tomadas por parte do MTE (Ministério do Trabalho e Emprego) pelos auditores fiscais, ao constatar irregularidades no que concerne a violação da legislação trabalhista, serão lavrado o auto de infração e resultante imposição de multa administrativa. Da mesma forma, é possível o encaminhamento de relatório ao Ministério Público do Trabalho para as medidas legais cabíveis.

Ao que tudo indica, os auditores-fiscais do trabalho ainda utilizam o Decreto $\mathrm{n}^{\circ}$ 3.298/99 para realizar o enquadramento da pessoa com deficiência, passando longe do novo conceito social de pessoa com deficiência e em fragrante descompasso com a Lei Maior, haja vista que o Tratado de Nova York possui, no ordenamento jurídico brasileiro, caráter constitucional.

Destarte, mesmo distando vários anos das mudanças constitucionais ocorridas com o ingresso da Convenção da ONU sobre pessoa com deficiência e, até mesmo com a publicação da Lei 13.146/2015, Estatuto da Pessoa com Deficiência, a atuação do Ministério do Trabalho demonstra anacronicidade, subtraindo da sociedade brasileira a possibilidade de fiscalização pró 
ativa, pela qual poderiam ser tuteladas inúmeras pessoas que porventura não correspondam ao conceito médico de deficiência, mas que o são socialmente.

Nesta pesquisa não foi encontrado qualquer caso que demonstrasse a utilização do novo conceito de pessoa com deficiência em atividade fiscalizatória, o que revela a necessidade urgente de mudança nos textos legais, que ora ainda são utilizados, para adaptação ao novo conceito e consequente inclusão de outros sujeitos no conceito social já citado.

\subsection{Da atuação fiscalizatória do Ministério Público do Trabalho}

O Ministério Público do Trabalho - MPT possui atribuições constitucionais de defesa da ordem jurídica justa, do regime democrático e dos interesses sociais e individuais indisponíveis, bem como de promoção da dignidade da pessoa humana, da valorização social do trabalho e da justiça social, nos termos do art. 127 e seguintes da Lei Maior.

Por meio de suas Coordenadorias, a exemplo da Coordenadoria Nacional da Igualdade, tem instituído Grupos de Trabalhos, visando o aperfeiçoamento de seus membros. Seguramente, o Parquet do Trabalho orienta seus membros para o novo conceito de Pessoa com Deficiência, o chamado conceito social. Caso algum membro do MPT ainda defenda o conceito médico de pessoa com deficiência, assim o faz com base na sua independência funcional, porquanto a orientação que vem sendo explicitada é a da necessidade de atualização da fiscalização dos direitos da pessoa com deficiência com base no conceito social, da Convenção da ONU, sobre direitos da pessoa com deficiência.

Exemplo elucidativo da mudança de paradigma foi dado pela Portaria PGT n ${ }^{\circ}$ 1472, de 20 de agosto de 2018 que expôs o posicionamento do MPT ${ }^{139}$ acerca do enquadramento das vítimas de escalpelamento no conceito de pessoa com deficiência, atualmente instituído pela Lei n ${ }^{\circ}$ 13.146, de 6 de julho de 2015, sem prejuízo das demais Notas Técnicas expedidas pelo MPT, as quais se pronunciam sobre outros assuntos relacionados.

Os escalpos ocorrem desde o fim da década de 60, quando o progresso levou aos ribeirinhos, principalmente do Norte do país, barcos a motor. A modernidade das viagens rápidas fez surgir o drama das mulheres escalpeladas, ainda pouco conhecido no restante do Brasil e ignorado durante décadas pelo poder público. Este enquadramento foi um grande passo para que estas centenas de

${ }^{139}$ NOTA TÉCNICA No 001 (GT Escalpelamento por Embarcações), DE 15 DE FEVEREIRO DE 2019 
mulheres possam vir a ter direito ao benefício mensal de um salário mínimo, caso preencham os demais requisitos do BPC. Deste modo, a partir deste reconhecimento que só foi possível pelo novo conceito social de deficiência, terão acesso as demais políticas públicas para pessoas com deficiência.

\subsection{Direito a benefício assistencial e previdenciários pagos pelo INSS}

A pessoa com deficiência poderá ter direito a benefício de caráter assistencial, previsto na Lei Orgânica da Assistência Social, titulado de benefício de prestação continuada - BPC ou benefício de caráter previdenciário, tais como auxilio doença o ou até mesmo aposentadoria por invalidez, reconhecidos e mantidos pelo Instituto Nacional do Seguro Social - INSS.

A redação original da Lei Orgânica da Assistência Social - "LOAS” (Lei 8.742, de 07 de dezembro de 1993) conceituava pessoa com deficiência como incapaz:

Art. 20. (...)

(...)

$\S 2^{\circ}$ Para efeitos de concessão deste benefício, a pessoa portadora de deficiência é aquela incapacitada para o trabalho e para a vida independente.

Michelle Dias Bublitz acertadamente defende que deficiência não deve ser confundida com incapacidade (BUBLITZ, 2012, p. 360). (FÁVERO apud SANTOS, 2012, p. 115). também critica o antigo conceito legal:

(...) Fez muito mal, pois definiu pessoa com deficiência, para efeito deste benefício, como aquela incapacitada para a vida independente e para o trabalho (art. 20, $\$ 2^{\circ}$ ). Tal definição choca-se, frontalmente, com todo o movimento mundial pela inclusão da pessoa com deficiência. Num momento em que se procura ressaltar os potenciais e as capacidades da pessoa com deficiência, por esta lei, ela deve demonstrar exatamente o contrário. (...) Muitos pais acabam impedindo seus filhos com deficiência de estudar e de se qualificar, justamente para não perderem o direito a esse salário mínimo. (FÁVERO apud SANTOS, 2012, p. 115).

Indo além, bastante salutar o pensamento de Ricardo Tadeu Marques da Fonseca que defende que a política assistencialista deve ser um instrumento de emancipação da pessoa com deficiência e que "a concessão do benefício em tela deveria ser acompanhada de envolvimento do beneficiário com as demais obrigações estatais inerentes à escola, à saúde, ao trabalho" (FONSECA, 2008, p. 270). 
Corrobora Marisa Ferreira dos Santos, no dilema "dar o peixe ou ensinar a pescar?”, a conclusão é que deve prevalecer o equilíbrio que assegure as condições mínimas necessárias à efetiva inclusão social:

(...) impossibilidade de se optar por apenas uma das duas condutas. Apenas "dar o peixe" leva a uma conduta caritativa que em nada contribui para a inclusão social da pessoa humana. Por outro lado, ninguém aprende nada de "estômago vazio" (SANTOS, 2012, p. 101).

Conforme já devidamente mencionado, a Convenção da ONU, Sobre os Direitos da Pessoa com Deficiência, assinada em Nova York, em 30 de março de 2007, trouxe conceito mais adequado ao mundo contemporâneo.

Destarte, a Procuradoria Geral da República ajuizou Ação de Arguição de Descumprimento de Preceito Fundamental - ADPF $n^{\circ} 182$ perante o Supremo Tribunal Federal para que fosse reconhecida a não recepção pela Constituição do ultrapassado conceito de deficiência do art. 20, $\S 2^{\circ}$, da Lei 8.742/93.

Acontece que a antiga concepção de que as pessoas com deficiência são incapazes para o trabalho e para a vida independente está tão arraigada no ordenamento jurídico que a recente Lei 12.435, de 06 de julho de 2011, insistiu, mais uma vez, em equiparar deficiência à incapacidade:

Art. 20. (...)

(...)

$\S 2^{\circ}$ Para efeitos de concessão deste benefício, considera-se:

(...)

II - Impedimentos de longo prazo: aqueles que incapacitam a pessoa com deficiência para a vida independente e para o trabalho pelo prazo mínimo de 2 (dois) anos.

O legislador ao perceber o anacronismo, o revogou pela Lei 12.470, de 31 de agosto de 2011. A oscilante e repentina alteração legislativa apenas comprova a dificuldade do legislador, como representante da sociedade, em assimilar o novo papel das pessoas com deficiência no mundo contemporâneo.

No mundo atual, em que a deficiência não é mais sinônimo de incapacidade, o conceito válido é, portanto, aquele trazido pela Lei 12.470, de 31 de agosto de 2011, que reproduziu ipsis litteris o conceito previsto na Convenção:

Art. 20. (..)

(...)

$\S 2^{\circ}$ Para efeito de concessão deste benefício, considera-se pessoa com deficiência aquela que tem impedimentos de longo prazo de natureza física, mental, intelectual ou 
sensorial, os quais, em interação com diversas barreiras, podem obstruir sua participação plena e efetiva na sociedade em igualdade de condições com as demais pessoas.

Saliente-se, apenas em 2011, e com dificuldades, a legislação ordinária entrou em consonância com a Convenção Internacional Sobre os Direitos da Pessoa com Deficiência, a despeito de já estar ratificada e aprovada desde 2008 e promulgada pelo Brasil, com status de Emenda Constitucional, desde 2009.

Registre-se mais uma vez que deficiência não se equipara com incapacidade e, outro avanço conceitual da Convenção foi não restringir o conceito de deficiência ao aspecto médico, mas incorporar o aspecto social, conforme observa (FONSECA, 2008, p. 263):

(...) o próprio conceito de pessoa com deficiência incorporado pela Convenção, a partir da participação direta de pessoas com deficiência levadas por Organizações Não Governamentais de todo o mundo, carrega forte relevância jurídica porque incorpora na tipificação das deficiências, além dos aspectos físicos, sensoriais, intelectuais e mentais, a conjuntura social e cultural em que o cidadão com deficiência está inserido, vendo nestas o principal fator de cerceamento dos direitos humanos que lhe são inerentes. (FONSECA, 2008, p. 263).

Conforme o novo conceito, além da deficiência sob o aspecto médico, que é o impedimento de natureza física, mental, intelectual ou sensorial que está na própria pessoa, há a deficiência da sociedade, cujas barreiras podem impedir a participação em condições de igualdade com as demais pessoas.

Contudo, seja para a concessão do BPC ou de benefícios previdenciários, a pessoa com deficiência será submetida a uma perícia médica, realizada por médico perito, do quadro de servidores públicos do INSS.

A perícia médica é uma atividade realizada no INSS para verificação médica com diversas finalidades que serão utilizadas administrativamente para caracterização ou não, conforme a legislação vigente no momento, do direito a um benefício previdenciário ou assistencial, dentre elas: a verificação da incapacidade laborativa consequente a traumas ou doenças para a concessão de benefícios por incapacidade; a verificação da invalidez para a concessão de benefícios assistenciais; a verificação do enquadramento da doença de que o examinado é portador em várias situações de direito a benefícios fiscais, tais como isenção de pagamento de imposto de renda para aposentados. 
É de competência exclusiva de um médico concursado e treinado internamente, que deve possuir conhecimentos de legislação previdenciária. Observe-se, o critério utilizado pelo INSS é ainda o critério médico e não o critério social, que é o atualmente em vigor.

Na concessão de benefício previdenciário apenas haverá o enquadramento da pessoa com deficiência por um perito médico do INSS. Neste caso, caberá absolutamente ao médico a realização do enquadramento ou não da pessoa como deficiente. Em relação ao BPC existirá na concessão do benefício um segundo profissional que é o assistente social, que ocupa o cargo de analista do seguro social com especialidade em assistência social.

Ocorre que o assistente social cuidará do segundo critério para a concessão do BPC, do critério renda "per capita" igual ou inferior a $1 \frac{1}{4}$ do salário mínimo. Deste modo, também em relação ao BPC o critério utilizado para a sua concessão pelo INSS é o ultrapassado critério médico.

Além de não equiparar deficiência com incapacidade, outro avanço conceitual da Convenção foi não restringir o conceito de deficiência ao aspecto médico, mas incorporar o aspecto social, conforme já citado.

Assim, de acordo com o novo conceito, além da deficiência sob o aspecto médico, que é o impedimento de natureza física, mental, intelectual ou sensorial que está na própria pessoa, há a deficiência da sociedade, cujas barreiras podem impedir a participação em condições de igualdade com as demais pessoas.

Urge uma completa revisão legislativa e procedimental no INSS para a substituição da Perícia Médica por uma Perícia Multidisciplinar, envolvendo vários profissionais, de diversas especializações, para a verificação da incapacidade sob o novel aspecto social.

\section{CONSIDERAÇÕES FINAIS}

O Tratado de Nova York, sobre os Direitos da Pessoa com Deficiência, foi o primeiro documento ratificado e aprovado pelo Brasil com status de Emenda Constitucional, a partir da qual é possível afirmar que houve a constitucionalização do conceito de pessoa com deficiência.

O grande avanço do novo conceito constitucional de pessoa com deficiência foi não tratar tais pessoas como incapazes para o trabalho e para a vida independente e não limitar a definição 
sob o aspecto médico acerca do impedimento físico, mental, intelectual ou sensorial, mas incluir o elemento social, mediante a análise do impedimento em interação com as barreiras sociais.

Contudo, o novo conceito é bastante genérico e está em evolução, o que acarreta o risco de violação ao princípio da isonomia nos enquadramentos efetuados nos casos concretos, principalmente quando adstrito apenas a uma análise médica em vez de uma avaliação multidisciplinar.

Identificar quem são as pessoas com deficiência a serem protegidas pelo Estado é relevante para a definição das políticas públicas para a tutela e a efetivação dos direitos humanos. A atuação de alguns órgãos estatais é imprescindível neste processo, principalmente dos ligados a áreas sensíveis como trabalho, previdência e assistência social. Neste sentido, a mudança do paradigma médico para social para enquadrar uma pessoa com deficiência é de suma importância para derrubar intolerâncias, perseguir os ideais de igualdade, universalização de direitos e a efetiva tutela dos direitos da pessoa com deficiência.

Nesse sentido, conclui-se que, afastada a noção de incapacidade do conceito de deficiência, as hipóteses exemplificativas previstas na legislação infraconstitucional constituem importante norte interpretativo.

De qualquer forma, o governo em conjunto com a sociedade civil poderá, a partir do novo paradigma social de deficiência, estabelecer critérios mais justos acerca dos impedimentos e das barreiras sociais que permitem o enquadramento ou a exclusão de uma pessoa do novo conceito de pessoa com deficiência.

No que pertine aos órgãos que foram analisados, constatou-se que apenas o Ministério Público do Trabalho, efetivamente, incorporou o novo conceito, chamado conceito social da pessoa com deficiência. Os auditores do trabalho e o INSS ainda trabalham na perspectiva do critério médico, a medida que em relação aos primeiros não houve mudanças nas legislações de fiscalização e em relação ao segundo, as pericias são realizadas apenas com o médico perito e não através de uma equipe multidisciplinar.

\section{REFERÊNCIAS}

ARAÚJO, Luiz Alberto David; COSTA FILHO, Waldir Macieira. A Lei 13.146/2015 (O Estatuto da Pessoa com Deficiência ou a Lei Brasileira de Inclusão da Pessoa com Deficiência) e sua efetividade.

Disponível

em: 
https://periodicos.unipe.br/index.php/direitoedesenvolvimento/article/view/298/280.

Acesso

em $12 / 05 / 2019$.

BALERA, Wagner. Noções preliminares de Direito Previdenciário. 2. ed. rev. ampl. São Paulo: Quartier Latin, 2010.

BARROS, Maria Magdala Sette de. Portadores de Deficiência e o concurso público. Boletim dos Procuradores da República. São Paulo. v. 4. n. 45. p. 22-4. Jan. 2002.

BUBLITZ, Michelle Dias. Conceito de pessoa com deficiência: comentário à ADPF 182 do STF. Revista da AJURIS. Porto Alegre. v.39. n.127. p.353-69. set. 2012.

CENSO 2010. Disponível em: http://censo2010.ibge.gov.br/noticiascenso?busca=1\&id=3\&idnoticia=2170\&view=noticia. Acesso em: 10 de maio. 2019

FÁVERO, Eugênia Augusta Gonzaga. Direitos das pessoas com deficiência: garantia de igualdade na diversidade. Rio de Janeiro: WVA, 2004, p. 189-190. In:

FARIAS, Cristiano Chaves; CUNHA, Rogério Sanches; PINTO, Ronaldo Batista. Estatuto da Pessoa com Deficiência comentado artigo por artigo. Salvador: JusPodivm, 2016.

FONSECA, Ricardo Tadeu Marques da. A ONU e o seu conceito revolucionário de pessoa com deficiência. LTr: Revista Legislação do Trabalho. São Paulo. v. 72. n. 3. p. 263-70. Mar. 2008.

LOPES, Laís Vanessa C. de Figueirêdo. Convenção da ONU sobre os Direitos das Pessoas com Deficiência: Nova ferramenta de inclusão. Revista do Advogado. São Paulo. v. 27. n. 95. p. 5664. Dez. 2007.

LOPES, Cristiane Maria Sbalquieiro; ROCHA, Geraldo Celso (Coord.). O MPT e a inserção da pessoa portadora de deficiência no mercado de trabalho: importância da fiscalização relativa às pessoas apresentadas como deficientes pela empresa; o caso da surdez. Revista do Ministério Público do Trabalho. Brasília. V. 11. N. 22. P. 60-70. Set. 2001.

LOPEZ, Gonzalo. Direito Educacional e o Processo de Inclusão: normas e diálogos para entender a escola do século XXI. Rio de Janeiro: Lumen Juris, 2018.

NEVES, Ana Fernanda. Os direitos das pessoas com deficiência no direito da União Europeia. Revista da Faculdade de Direito da Universidade de Lisboa. Lisboa. V. 51. N. 1/2. P. 93-125. 2010.

PERSIANI, Mattia. Direito da Previdência Social. 14. ed. São Paulo: Quartier Latin, 2009.

RIBEIRO, Lauro Luiz Gomes. Manual dos Direitos da Pessoa com Deficiência. São Paulo: Verbatim. 2010. 
RIBEIRO, Lauro Luiz Gomes; GUGEL, Maria Aparecida; MACIEIRA, Waldir (organizadores). Deficiência no Brasil: uma abordagem integral dos direitos das pessoas com deficiência. Florianópolis: Obra Jurídica, 2007.

RODRIGUES, Maria de Lourdes Alves. Curso de Formação de Conselheiros em Direitos Humanos. Disponível em http://www.dhnet.org.br/dados/cursos/dh/cc/a_pdf/modulo3-tema5aula1.pdf. Acesso em 30/03/2015.

SANTOS, Marisa Ferreira dos; LENZA, Pedro (Coord.). Direito Previdenciário esquematizado. 2. ed. rev. atual. São Paulo: Saraiva, 2012.

VERDÉLIO, Andreia. Apenas $1 \%$ dos brasileiros com deficiência está no mercado de trabalho. Agência Brasil, Brasília, 26 de agosto de 2017. Disponível em: http://agenciabrasil.ebc.com.br/direitos-humanos/noticia/2017-08/apenas-1-dos-brasileiros-comdeficiencia-esta-no-mercado-de. Acesso em 30/04/2019

\title{
THE NEW CONCEPT OF DISABLED PEOPLE AND ITS APPLICABILITY BY STATE RIGHTS SUPERVISORS OR RECOGNIERS
}

\begin{abstract}
This article aims to address the conceptual change of people with disabilities and the difficulty of assimilating this change in the inspection bodies or recognizers of state rights. The New York Convention, on the rights of persons with disabilities, which entered the Brazilian legal system with normal constitutional status, according to the legislative process provided for in art. $5, \S 3$, of the Federal Constitution, substantially changed Brazilian rules. From then on, it is intended that the permanent inclusion process is more effective, overthrowing intolerances, pursuing the ideals of equality, universalization of rights and the effective protection of the rights of people with disabilities, since they have their situation more or less aggravated, considering the conditions of the environment are more or less favorable. Thus, two inspection bodies will be analyzed, the Labor Precincts and the Public Ministry of Labor and the National Social Security Institute - INSS, as a rights recognizer. To this end, it will be observed, through qualitative research, the legislation that has been applied by these state bodies, after the referred conceptual change.
\end{abstract}

Key words: New conception. Rights. Disability People. State inspection. Welfare benefit. 